\title{
Mechanical Properties and Flame Retardancy of Epoxy Resin/ Nanoclay/Multiwalled Carbon Nanotube Nanocomposites
}

\author{
Tuan Anh Nguyen $\mathbb{D}^{1},{ }^{1}$ Quang Tung Nguyen, ${ }^{1}$ and Trong Phuc Bach ${ }^{2}$ \\ ${ }^{1}$ Faculty of Chemical Technology, Hanoi University of Industry (HaUI), No. 298 Cau Dien, North District Tu Liem, \\ Hanoi, Vietnam \\ ${ }^{2}$ Hanoi University of Science and Technology, No. 1 Dai Co Viet Road, Hanoi, Vietnam \\ Correspondence should be addressed to Tuan Anh Nguyen; anhnt@haui.edu.vn
}

Received 19 February 2019; Revised 6 May 2019; Accepted 23 May 2019; Published 16 June 2019

Guest Editor: Thanh-Dong Pham

Copyright (C) 2019 Tuan Anh Nguyen et al. This is an open access article distributed under the Creative Commons Attribution License, which permits unrestricted use, distribution, and reproduction in any medium, provided the original work is properly cited.

\begin{abstract}
This paper reports the improvement of the mechanical properties and flame retardant properties of epoxy Epikote 240/nanoclay $\mathrm{I} .30 \mathrm{E} /$ multiwalled carbon nanotube nanocomposite prepared by mechanical stirring method combined with ultrasonic vibration, nanoclay I.30E content $(1 ; 2 ; 3$ wt.\%) and content of MWNT $(0.01 ; 0.02 ; 0.03$ wt.\%). When burned, MWCNT reduces degradation speed of epoxy Epikote 240 resin and increases the char yield, and nanoclay acts as an energy storage medium to hinder the heat transfer in epoxy resin. The limiting oxygen index value and UL94 test indicated improvement of flame retardancy of the nanocomposites. The results exhibit the potentiality of these based epoxy Epikote $240 \mathrm{resin} /$ nanoclay I.30E/MWCNTs nanocomposites for multifaceted advanced applications. These fillers can produce environmental friendly products with high thermal and mechanical properties.
\end{abstract}

\section{Introduction}

Currently, multicarbon carbon nanotubes and nanoclay are the stuffing widely used because they improve both the fireretardant properties and mechanical properties of epoxy plastic; they do not create toxic fumes or smoke corrosion during burning process, unlike common fire-retardant materials based on halogen compounds [1,2]. Some studies have investigated the fire resistance of epoxy-based nanocomposite materials in MWCNTs and stated that, for MWCNTs, at the content of 2 and $4 \%, 5 \%$ by weight, the fire resistance of the material increases. It is explained that the formation of coal coating on the surface of the sample separated from oxygen in the environment leads to the prevention of the development of flame [3,4]. Therefore, the improvement of fire resistance of materials is clearly shown. For nanoclay additives, Cevdet et al. conducted research on mechanical properties, flammability, and structural morphology of epoxy/clay nanocomposite; nanoclay has been prepared with the content of $0.5,1,2$, and $3 \%$ by weight [5].
This work focuses on the study of flammability and mechanical properties of epoxy Epikote 240 substrate nanocomposites materials by adding MWCNT (0.02 wt.\%) and nanoclay I.30E ( $2 \mathrm{wt} . \%)$, a small amount compared to the other works announced.

\section{Materials and Methods}

2.1. Materials. The epoxy Epikote 240 (EP240) was provided by Shell Chemicals (USA). EP240 is a low viscosity, based on a belnd of bisphenol A resin and bisphenol B resin, contented epoxy group of $24.6 \%$, molecular weight $(\mathrm{Mw})$ of $5100-5400 \mathrm{mmol} / \mathrm{kg}$, density of $1.12 \mathrm{~g} / \mathrm{ml}$, and viscosity at $25^{\circ} \mathrm{C}$ to be $0.7-1.1 \mathrm{~Pa} \cdot$. s. Diethylenetriamine (DETA) received from Dow Chemical (USA) has a density of $0.95 \mathrm{~g} / \mathrm{ml}$ boiling point of $207^{\circ} \mathrm{C}$ and $\mathrm{Mw}$ of $103 \mathrm{mmol} / \mathrm{kg}$ and is used directly without any further purification. Multiwalled carbon nanotubes (MWCNTs) of Showa Denko (Japan). Synthesized by catalyst deposition method, MWCNTs have an average diameter of $40-45 \mathrm{~nm}$, an average length of $3 \mu \mathrm{m}$, 
and a density of $0.08 \mathrm{~g} / \mathrm{cm}^{3}$. Nanomer ${ }^{\circledR}$ I.30E nanoclay (Nanocor USA) is a surface-changing montmorillonite (MMT) mineral that will disperse into nanoparticles in epoxy resin systems. Dispersion creates a mixture close to the molecule often called nanocomposite. This new composite model shows enhanced strength, heat and barrier properties. I.30E is provided in the form of white powder dispersed into thin particles that are almost transparent in the plastic matrix. Type E raw glass cloth $600 \mathrm{~g} / \mathrm{m}^{2}$ (China).

\subsection{Methods}

2.2.1. Sample Preparation and Characterization. The nanoclayMWCNT hybrids were prepared according to Table 1. MMT (1, 2, and 3 wt.\%) and MWCNT (0.01, 0.02, and 0.03 wt.\%) were dispersed in epoxy Epikote 240 resin, stirred at $3500 \mathrm{rpm}$ for $8 \mathrm{~h}$ (HS-100T, WiseStir, Korea). In order to break up the MWCNT bundles and disperse the additives, sonication was performed using an ultrasonic bath (Elmasonic S300 H, $37 \mathrm{kHz}$, Germany) for $6 \mathrm{~h}, 65^{\circ} \mathrm{C}$. After the mixtures were homogenously mixed, the curing agent DETA (amount of curing agent was calculated by epoxy content of epoxy resin, stirred for $15 \mathrm{~min}$ at $200 \mathrm{rpm} / \mathrm{min}$ ) was added, and the mixtures were moulded for curing. The mould was coated with a uniform thin film of silicone-a releasing agent for easy removal of cured specimen. The samples were cured at room temperature for about $24 \mathrm{~h}$ and further cured at $80^{\circ} \mathrm{C}$ in the laboratory oven for $3 \mathrm{~h}$. Then, the samples were removed from the mould, and after 7 days, mixture was analyzed and mechanical properties measured.

Produce glass/epoxy nanomaterials. The glass/epoxy nanomaterials are fabricated using a combination of manual hot and hot compressing techniques. The layers of glasswoven fabrics are stacked into 9 layers, and the orientation of the yarn in the fabric is kept constant.

\subsubsection{Characterizations}

(i) Limiting Oxygen Index (LOI) according to ASTM D2863-12 and JIS K720 standard (Japan): the sample bars used for the test were $150 \times 6.5 \times 3 \mathrm{~mm}^{3}$.

(ii) The Horizontal Burning tests (UL-94HB) : Standard bar specimens are $125 \pm 5 \mathrm{~mm}$ in length with $13.0 \pm 0.5 \mathrm{~mm}$ width and provided with the minimum thickness of $3.0(-0.0+0.2) \mathrm{mm}$ (ASTM D635-12).

(iii) Combustion Resistance: The apparatus is specifically designed for combustion and incandescence resistance of thermoplastics, thermosetting, rigids, and laminates. The apparatus was designed and built to meet the following standards: ASTM D 757; specimen's dimensions $3.17 \times 12.7 \times 121 \mathrm{~mm}$; maximum temperature of $950^{\circ} \mathrm{C}$.

(iv) The combustion rate was measured by COMBUSTION RESISTANCE COD 6145000 according to the ASTM D757-77 standard. Specimen's dimensions are $3.17 \times 12.7 \times 121 \mathrm{~mm}^{3}$.
TABLE 1: Taguchi orthogonal array of designed experiments based on the coded levels.

\begin{tabular}{lccc}
\hline Trial & Sample code & $\begin{array}{c}\text { MWCNT content } \\
\text { (wt.\%) }\end{array}$ & Nanoclay content (wt.\%) \\
\hline 1 & EP1 & 0.01 & 1 \\
2 & EP2 & 0.02 & 1 \\
3 & EP3 & 0.03 & 1 \\
4 & EP4 & 0.01 & 2 \\
5 & EP5 & 0.02 & 2 \\
6 & EP6 & 0.03 & 2 \\
7 & EP7 & 0.01 & 3 \\
8 & EP8 & 0.02 & 3 \\
9 & EP9 & 0.03 & 3 \\
\hline
\end{tabular}

Mechanical tests were conducted on at least five specimens by a $100 \mathrm{kN}$ universal testingmachine (INSTRON5582, USA).

(i) Flexural properties were determined by using threepoint bending test specimens with dimensions of $100 \times 15 \times 4 \mathrm{~mm}$ according to ISO 178 .

(ii) Compressive properties were determined by using three-point bending test specimens with dimensions of $15 \times 10 \times 10 \mathrm{~mm}$ according to ISO 178-1993.

(iii) Izod Impact Strength was determined according to the ASTM D265 satndard in Tinius Olsen (USA). The standard specimen for ASTM is $64 \times 12.7$ $\times 3.2 \mathrm{~mm} \quad(2(1 / 2) \times 1 / 2 \times 1 / 8$ inch $)$, Izod Sample Geometry: $2 \mathrm{~mm}$.

(iv) Tensile properties were determined by using threepoint bending test specimens according to ISO 178 . Specimen size according to ISO is $10 \mathrm{~mm} \times 4 \mathrm{~mm}$ $\times 80 \mathrm{~mm}$.

(v) The morphology of the samples was carried out by scanningelectron microscope (SEM, Evacseq error codes, S-4800, Japan). Structuralcharacterizations were studied by X-ray diffraction (XRD, D8Advance, Brucker, Germany).

\section{Results and Discussion}

3.1. Distribution of $M M T / M W C N T$ Additives in the Epoxy Complex. Morphology of the nanocomposites is as follows: Figure 1 presents cross sections of the EP1, EP2, and EP3 samples to investigate the dispersion.

The fracture surface is so rough, proving high strength of the material lead to it is difficult to destroy. MWCNTs and nanoclay play so important a role in limiting the development of the fracture (Figures 1(a)-1(c); Figures 2(a)-2(c); and Figures 3(a)-3(c)). Therefore, in order to break the material, the force must be higher. Figures 1-3 show that there were rough surfaces in the regions including nanoparticles in comparison to other regions with higher and flatter cracks (Figure 1(c)). For the distribution of nanoparticles, EP5 sample (Figure 2(b)) had the uniform distribution of nanoparticles in epoxy resin E 240 and a so rough fracture surface. FE-SEM images in Figures 1-3 


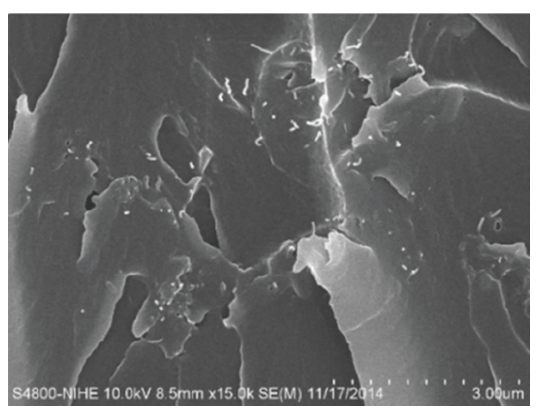

(a)

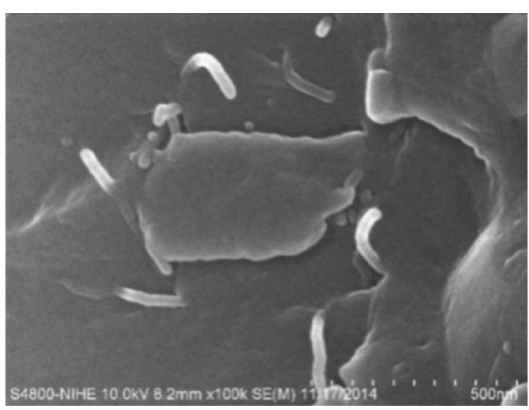

(b)

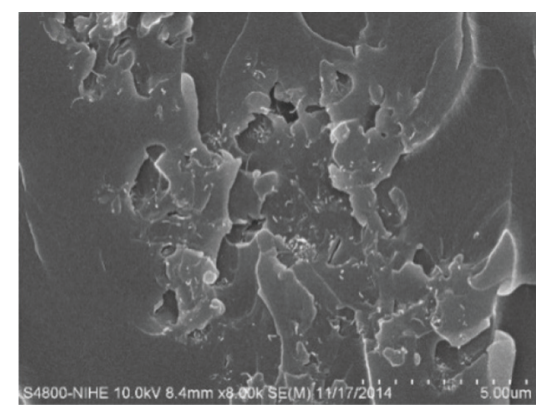

(c)

Figure 1: Cross-section images of (a) EP1, (b) EP2, and (c) EP3.

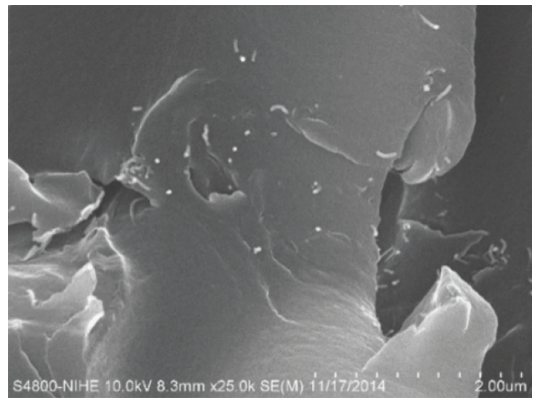

(a)

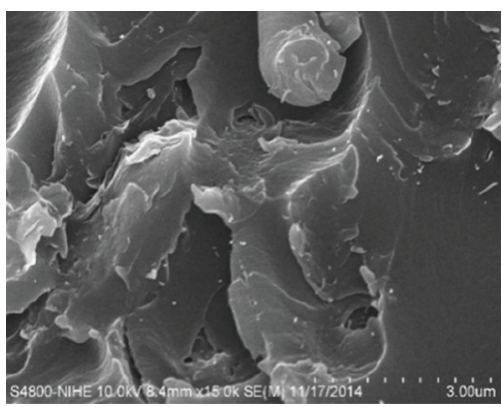

(b)

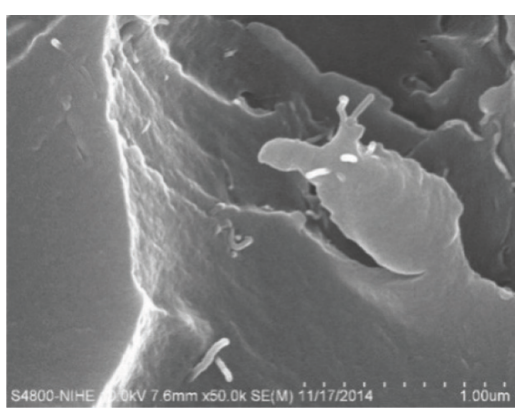

(c)

Figure 2: Cross-section images of (a) EP4, (b) EP5, and (c) EP6.

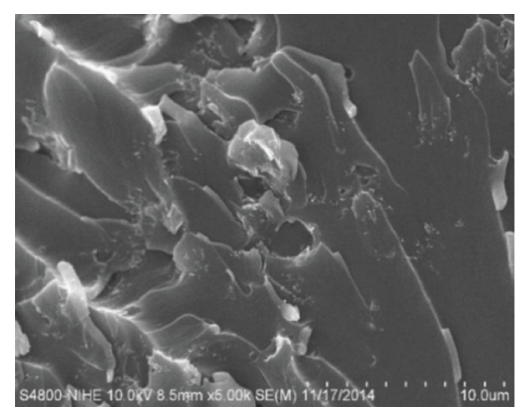

(a)

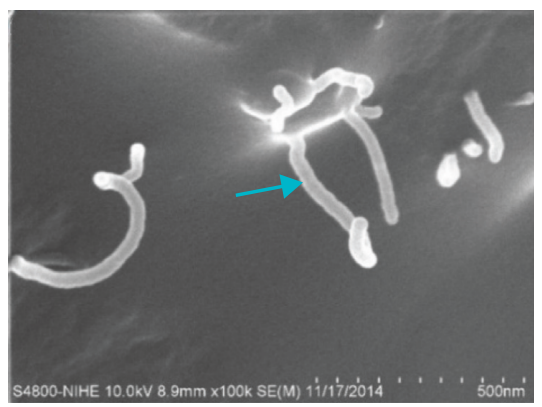

(b)

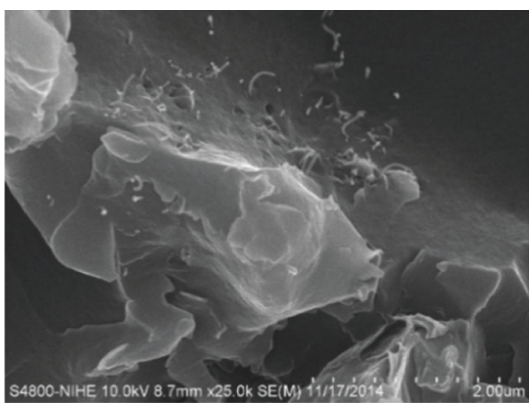

(c)

Figure 3: Cross-section images of (a) EP1, (b) EP2, and (c) EP3.

indicate that nanoparticles were well stuck on epoxy resin E 240. Because, after breaking the sample, nanoparticles were still maintained on the surfaces and covered by the resin. Moreover, FE-SEM images of the fracture surfaces of tensile samples show that cracks often begun at nanoparticles' agglomeration.

In the magnitude of 100.000 times, the uniform distribution of MWCNTs in epoxy resin E 240 is so clearly observed, and there was no nanoparticles' agglomeration (Figures 4(a) and 4(b)). Figure 4(c) also shows the uniform distribution of nanoclay in epoxy resin. So, MWCNTs and nanoclay were quite well distributed in epoxy resin E 240 by stirring combined with the ultrasonic vibration. The distribution pattern of the nanoclay in the polymer matrix can be identified by the X-ray diffraction patterns of the nanocomposites (Figure 5). In Figure 4, the captured surfaces not only observe the dispersion of MWCNTs but also nanoclay, though not in any strict order but the thermal conductivity of nanomaterials as well as coal layers. The formation after fire can fully explain to us the flame flammability and heat transfer of composite materials with additives MWCNTs/nanoclay I.30E. The difference in the addition of MWCNTs and nanoclay helped the nanoparticles/ epoxy mixtures not easily get melted as for pure epoxy resin samples, even at high temperatures. If a layer of ash can be formed during combustion of the polymer, it can act as an insulating sheet, limiting heat transfer from the source to the polymer. Therefore, the number and texture of the ash layers is important to limit the combustion of the polymer. In Figure $4(\mathrm{~b})$, it can be seen that the MWCNTs are evenly 


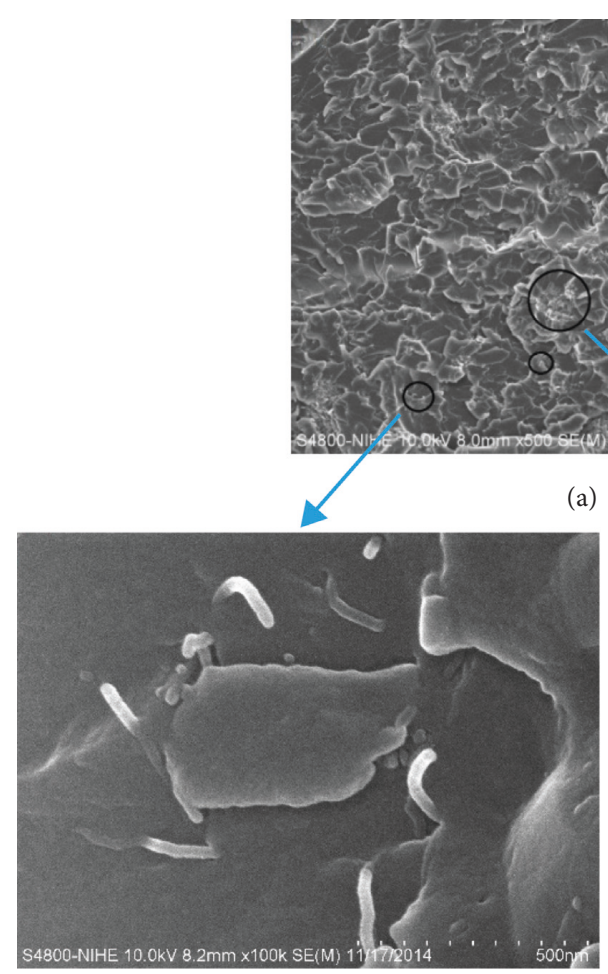

(b) (a)

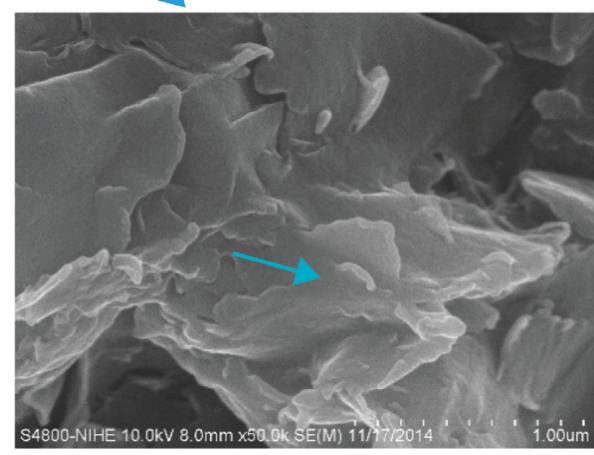

(c)

FIGURE 4: FE-SEM image of broken surface material MWCNTs/nanoclay I.30E/epoxy E 240. (a) 500 times, (b) 100,000 times, and (c) 50,000 times.

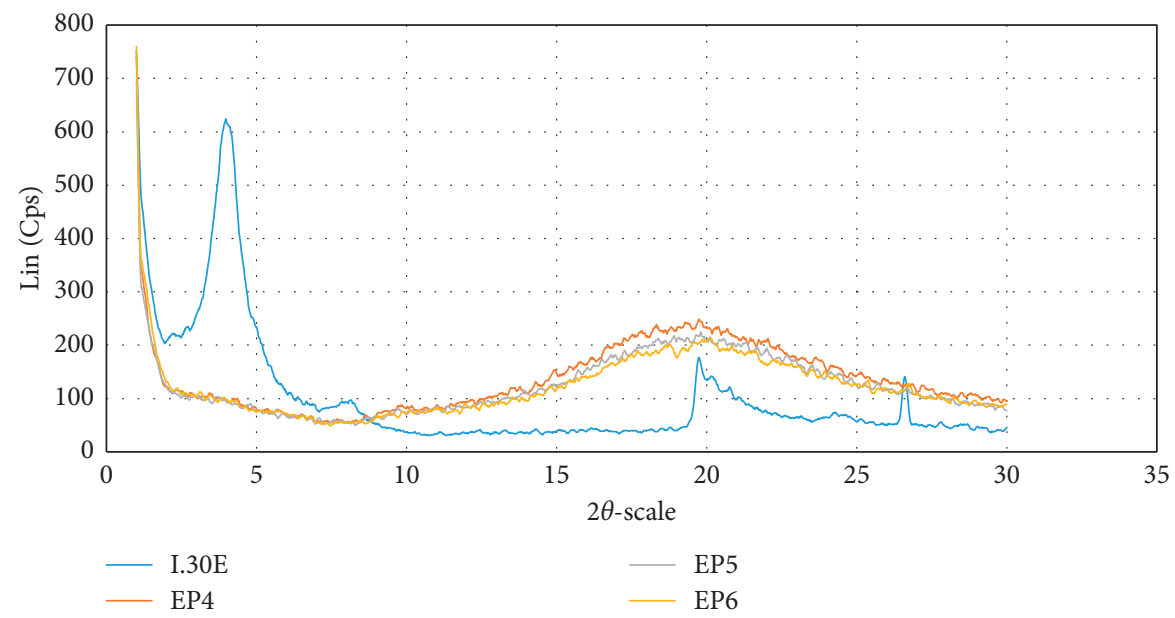

FIGURE 5: XRD patterns for I.30E: nanoclay (MMT), EP4: nanocomposite of epoxy resin with 2 wt.\% MMT/0.01 wt.\%, EP5: nanocomposite of epoxy resin with 2 wt.\% MMT/0.02 wt.\%, EP6: nanocomposite of epoxy resin with 2 wt.\% MMT/0.03 wt.\%; nanoclay (MMT) shows a

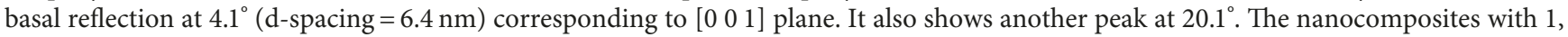
2.5, and 5 wt.\% clay exhibit no Braggs scattering, indicating that silicate layers of organoclay may be exfoliated as they do not have any regular repeating distance.

dispersed in epoxy; besides, nanoclay layers (Figure 4(c)) are also dispersed evenly [6-8].

3.2. Mechanical Properties. Presence of multiwalled carbon nanotubes in epoxy base materials reduces partial free volume and fills in the gaps and defects formed from the epoxy resin curing process [9]. Thus increasing thermal stability, fire retardation as well as mechanical durability. Because if there are gaps in the epoxy material (defects), it is the higher flare of combustion.

Uniform dispersion and perfect adhesion of MWCNTs in epoxy plastic is the main reason to increase the mechanical properties of epoxy resin. In this work, multiwalled 
carbon nanotubes were relatively uniformly dispersed, with no cumulative contraction observed in FE-SEM images. Cracks start from interface, and then, the MWCNTs are affected by the outside [10]. Improved mechanical properties are shown in this work. MWCNTs increase the ability to withstand external forces. MWCNTs in the epoxy material matrix have prevented the development of microscopic cracks, altering the movement trajectory of the crack [11]. The spread of cracks is prevented, clearly displayed in Figure 6 (results of our research related to this work).

Mechanical strength of samples was increased with the contents of nanoclay and MWCNTs of $2 \%$ and $0.02 \%$ by weight, respectively. For other contents, mechanical strength was less increased, due to limiting of the contribution (Table 2). If there are layers of ash formed from burning polymers, they can play as heat-isolation layers, restricting the heat transfer from heat resources to polymers. Thus, the number and structure of ash layers play an important role to restrict the combustion of polymers.

The degree of dispersion of MWCNTs and nanoclay in epoxy E 240 is a decisive factor for fire resistance and mechanical properties of nanocomposites. At other ratios, mechanical properties tend to decrease because of the limited dispersion capacity, so the mechanical strength is slightly reduced. Particularly, for the level of distribution of nanoparticles, sample MWCNTs/nanoclay $=0.02 / 2$ (EP5) has nanoparticles distributed evenly in epoxy E 240 resin. This can be explained by the blending level of MWCNTs/ nanoclay $=0.02 / 2$ (EP5), the material achieves high compatibility, and the structure is more compact than the rest. Therefore, the mechanical properties and the fire retardancy increase. As for other mixing ratios, it may be due to the residual mass of MWCNTs or nanoclay remaining after fabrication. This leads to the creation of a lower compatibility structure so that when there is a high-temperature impact, the material is easily destroyed at the points, the structure area is unstable, the combustion rate is high, and the mechanical strength is reduced.

3.3. Flame Retardancy. The LOI, representing the lowest oxygen volume content for sustaining the flame in an environment, was used for quantifying the flame retardancy of epoxy resin. The oxygen volume content in ambient atmosphere is about $21 \%$. Therefore, a material exhibiting its LOI above 21 might show flame-retardant property. Generally, materials with LOI values higher than 26 might show selfextinguishing behavior and were considered to be highly flame-retardant. The results of LOI and UL-94 for epoxy resin and its composites are listed in Table 3 . Table 3 shows that the best results were achieved with $0.02 \%$ and $2 \%$ by weight of MWCNTs and nanoclay, respectively. The result was LOI of $25 \%$, the burning rate of $20.5 \mathrm{~mm} / \mathrm{min}$, and UL $94 \mathrm{HB}$ of $18.6 \mathrm{~mm} / \mathrm{min}$. The quality of flame-protecting layers of materials and characteristics of burned material's surfaces was evaluated by FE-SEM method (Figures 1(a) and 2-4).

With epoxy resin, oxidizing agents are easy to attack, and therefore, this plastic sample will easily ignite. MWCNTs have formed a thin film covering the outside of the material.
Although thin, it is interwovenly complicated by MWCNTs with the ability to conduct heat along the pipe as well as the heat resistance in the middle of the tubes very well. This leads to the fact that the oxidizing agents are difficult to penetrate and help the material's fire resistance, especially when the protective coal layer is formed [4].

When MWCNTs are well dispersed in the substrate, the coal layer produced will be more evenly spread over the surface. Also, this barrier will minimize the ability to catch fire as well as exposure to air oxygen. At the same time, the tendency to reignite is reduced, making the fire impossible to spread and fade [4]. The compact structure also increases the fire resistance of the material.

A barrier-like barrier is created by nanoclay elements that are heat-resistant and heat-retaining, which slows down the diffusion of oxygen and prevents flammable substances from burning in the material. The process of heat transfer to the material has therefore reduced the time to sustain the combustion. The formation of a silicate ash layer evenly spread on the surface of nanocomposite has prevented the penetration of the flame to help the combustion process be extinguished.

In the case of MWCNTs/nanoclay/epoxy resin materials, there was no crack in flat surfaces (Figure 7(b)), in which when the epoxy material is burned, the surface of the burning gas has many cracks (Figure $7(\mathrm{a})$ : neat epoxy). The ash layers formed from burning MWCTNs and nanoclay in surfaces play an important role like heat shields to prevent the heat transfer. If there are layers of ash formed from burning polymers, they can play as heatisolation layers, restricting the heat transfer from heat resources to polymers. Thus, the number and structure of ash layers play an important role to restrict the combustion of polymers. It can delay the heat transfer from heat resources, leading to more slow increase temperature. A phenomenon observed in experiments with the presence of MWCNTs was the dripping of samples when burned, proving the important role of MWCNTs in improving the fire-retardant properties of materials. It can delay the heat transfer from heat resources, leading to more slowly increase temperature. A phenomenon observed in experiments with the presence of MWCNTs was the dripping of samples when burned, proving the important role of MWCNTs in improving the fire-retardant properties of materials.

If the nanocontent increases, the viscosity increases and affects dispersion. If the nanocontent exceeds the threshold leading to a decrease in the compatibility with epoxy base resin and the accumulation of nanoparticles (Figures 8 and 9), the amount of residual nanomaterial creates holes (Figure 10) inside Whether these factors are responsible for the reduction of mechanical strength and fire resistance. In the case of small nanoadditives, the mechanical strength and fire resistance are not met.

On the other hand, if the dispersion technique is not suitable, there will be nanoparticles aggregation in some places right above the interface of nano-epoxy E 240. There are residual nanoparticles, forming a separate phase of breaking down, where cracks are formed and grown, 

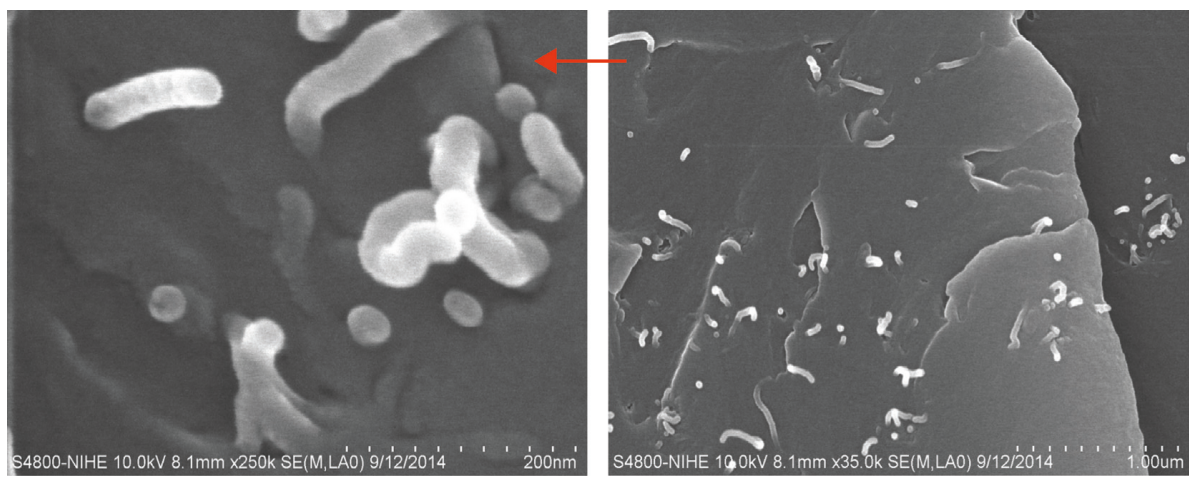

Figure 6: FE-SEM micrographs of MWCNTs 0.02 wt.\%/nanoclay 2 wt.\%/epoxy Epikotre 240 nanocomposites.

TABLE 2: Optimum mechanical properties of epoxy/nanoclay/MWNT nanocomposites from fine tuning experiments.

\begin{tabular}{|c|c|c|c|c|c|c|c|}
\hline Trial & Sample code & $\begin{array}{c}\text { MWCNT } \\
\text { content } \\
\text { (wt.\%) }\end{array}$ & $\begin{array}{c}\text { Nanoclay } \\
\text { content } \\
\text { (wt.\%) }\end{array}$ & $\begin{array}{l}\text { Tensile strength } \\
(\mathrm{MPa})\end{array}$ & $\begin{array}{c}\text { Flexural } \\
\text { strength } \\
(\mathrm{MPa})\end{array}$ & $\begin{array}{l}\text { Compressive strength } \\
(\mathrm{MPa})\end{array}$ & $\begin{array}{c}\text { Impact } \\
\text { strength } \\
\left(\mathrm{kJ} / \mathrm{m}^{2}\right)\end{array}$ \\
\hline 1 & $\begin{array}{l}\text { Neat epoxy } \\
\text { resin }\end{array}$ & 0.00 & 0 & $55.90 \pm 0.6$ & $86.75 \pm 0.5$ & $156.08 \pm 0.3$ & $7.11 \pm 0.45$ \\
\hline 2 & EP1 & 0.01 & 1 & $87.56 \pm 0.5$ & $93.70 \pm 0.5$ & $205.99 \pm 0.4$ & $10.60 \pm 0.50$ \\
\hline 3 & EP2 & 0.02 & 1 & $88.34 \pm 0.6$ & $93.60 \pm 0.4$ & $195.23 \pm 0.3$ & $12.70 \pm 0.45$ \\
\hline 4 & EP3 & 0.03 & 1 & $90.42 \pm 0.4$ & $94.26 \pm 0.5$ & $216.08 \pm 0.2$ & $19.70 \pm 0.60$ \\
\hline 5 & EP4 & 0.01 & 2 & $93.43 \pm 0.6$ & $98.56 \pm 0.3$ & $203.76 \pm 0.5$ & $21.54 \pm 0.70$ \\
\hline 6 & EP5 & 0.02 & 2 & $95.50 \pm 0.5$ & $115.45 \pm 0.5$ & $219.10 \pm 0.3$ & $22.30 \pm 0.45$ \\
\hline 7 & EP6 & 0.03 & 2 & $92.12 \pm 0.8$ & $108.60 \pm 0.3$ & $203.51 \pm 0.6$ & $19.70 \pm 0.60$ \\
\hline 8 & EP7 & 0.01 & 3 & $93.45 \pm 0.6$ & $108.90 \pm 0.6$ & $212.08 \pm 0.4$ & $20.27 \pm 0.50$ \\
\hline 9 & EP8 & 0.02 & 3 & $90.67 \pm 0.4$ & $103.60 \pm 0.4$ & $202.13 \pm 0.2$ & $18.13 \pm 0.40$ \\
\hline 10 & EP9 & 0.03 & 3 & $90.67 \pm 0.5$ & $102.78 \pm 0.2$ & $200.10 \pm 0.3$ & $16.04 \pm 0.70$ \\
\hline
\end{tabular}

TABle 3: Results of flammability tests (reaction to small flame): oxygen index (OI) and UL 94 for nanocomposites.

\begin{tabular}{|c|c|c|c|c|c|c|}
\hline Trial & Material & $\begin{array}{c}\text { MWCNT } \\
\text { content (wt.\%) }\end{array}$ & Nanoclay content (wt.\%) & LOI (vol. $\% \mathrm{O} 2 \pm 2 \sigma)$ & Combustion rate $(\mathrm{mm} / \mathrm{min})$ & $\begin{array}{c}\text { UL94 HB } \\
(\mathrm{mm} / \mathrm{min})\end{array}$ \\
\hline 1 & Neat epoxy resin & 000 & 0 & $20.6 \pm 0.3$ & 28.41 & Not rated (NR) \\
\hline 2 & $\mathrm{EP} 1$ & 0.01 & 1 & $22.8 \pm 0.3$ & 24.25 & $25.78(\mathrm{HB})$ \\
\hline 3 & EP2 & 0.02 & 1 & $24.2 \pm 0.5$ & 23.01 & $22.35(\mathrm{HB})$ \\
\hline 4 & $\mathrm{EP} 3$ & 0.03 & 1 & $24.6 \pm 0.4$ & 22.45 & $22.03(\mathrm{HB})$ \\
\hline 5 & $\mathrm{EP} 4$ & 0.01 & 2 & $24.2 \pm 0.3$ & 22.34 & $20.01(\mathrm{HB})$ \\
\hline 6 & EP5 & 0.02 & 2 & $25.0 \pm 0.3$ & 20.05 & $18.60(\mathrm{HB})$ \\
\hline 7 & EP6 & 0.03 & 2 & $24.6 \pm 0.5$ & 19.03 & $18.85(\mathrm{HB})$ \\
\hline 8 & EP7 & 0.01 & 3 & $24.2 \pm 0.4$ & 20.45 & $19.65(\mathrm{HB})$ \\
\hline 9 & EP8 & 0.02 & 3 & $24.6 \pm 0.6$ & 21.43 & $18.68(\mathrm{HB})$ \\
\hline 10 & EP9 & 0.03 & 3 & $24.6 \pm 0.3$ & 20.80 & $18.76(\mathrm{HB})$ \\
\hline
\end{tabular}

reducing mechanical properties and fire resistance of the materials (Figures 10 and 11).

3.4. E-Glass/Epoxy Nanocomposites. Figures 12(a)-12(d) show the magnified SEM micrographs of fractured fibers. Evident from these micrographs, the fiber in e-glass/epoxy composites sample contains considerable amount of epoxy resin residue and rougher fracture surface in comparison to control samples. Similarly, in 2 wt.\% nanoclay/e-glass/epoxy composites samples, distributed resin residue and rougher fracture surface were observed but not as profound as in
0.02 wt.\% MWCNTs/e-glass/epoxy composites counterpart. In 2 wt.\% nanoclay/0.02 wt.\% MWCNTs/e-glass/epoxy composite samples, there are mixed regions of dispersed and agglomerated MWCNTs. The interfacial bonding in a welldispersed region may have improved the interfacial bonding, whereas the agglomerated region contributed to the initiation of fracture. As a result, a distributed residue of resin, rougher fracture surface (Figure 12(d)), and several cracks (Figure 12(d)) were observed in $2 \mathrm{wt} . \%$ nanoclay/ 0.02MWCNTs/e-glass/epoxy composites sample.

The purpose of the research team is to manufacture epoxy E 240 substrates based on MWCNTs and nanoclay 


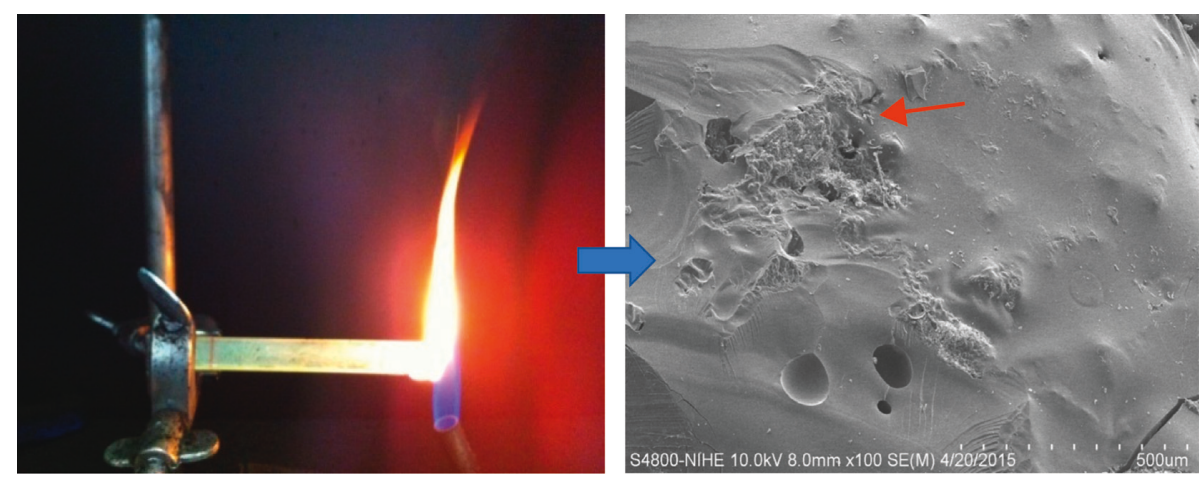

(a)
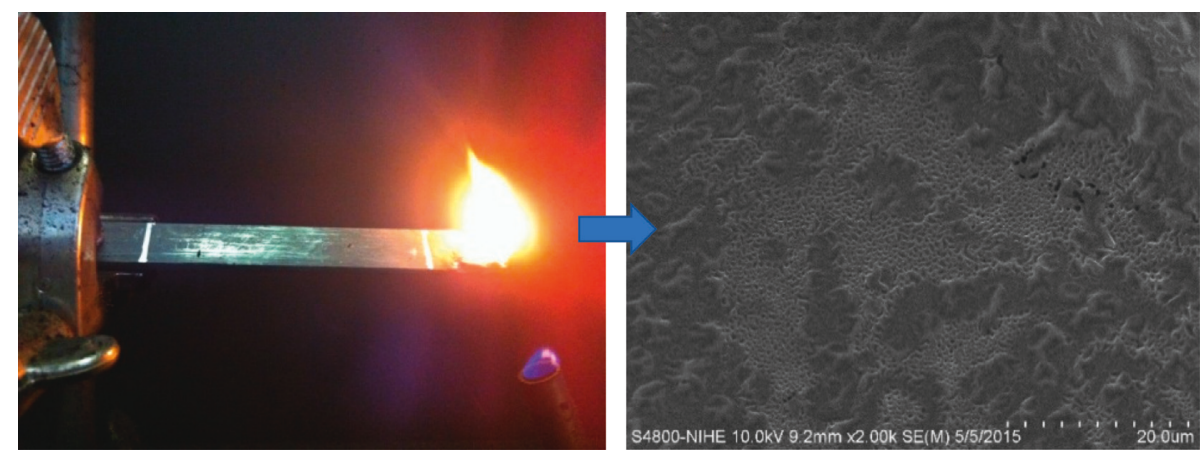

(b)

Figure 7: SEM images of the residual of (a) neat epoxy and (b) composites MWCNTs 0.02 wt.\%/nanoclay 2 wt.\%/epoxy resin (UL-94HB).

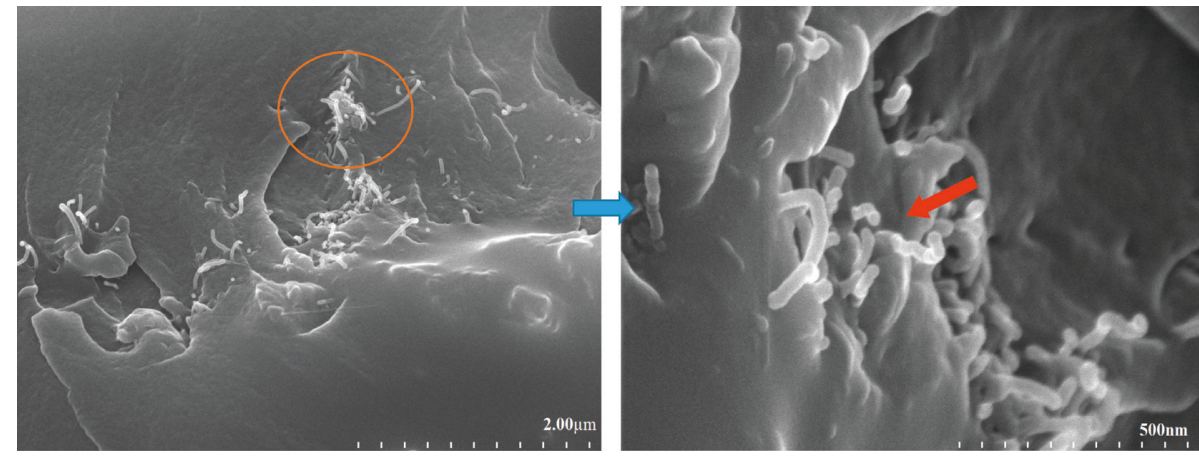

FIGURE 8: FE-SEM image of nanocomposite material MWCNTs/nanoclay mixing ratio: 0.03/2 (percentage mass).

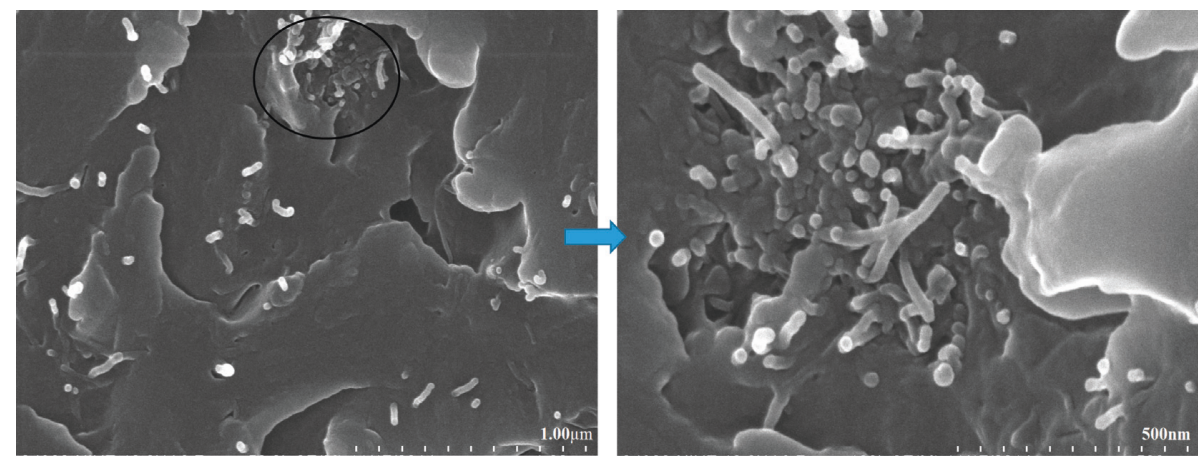

FigURE 9: FE-SEM image of nanocomposite material MWCNTs/nanoclay mixing ratio: 0.03/3 (percentage mass). 


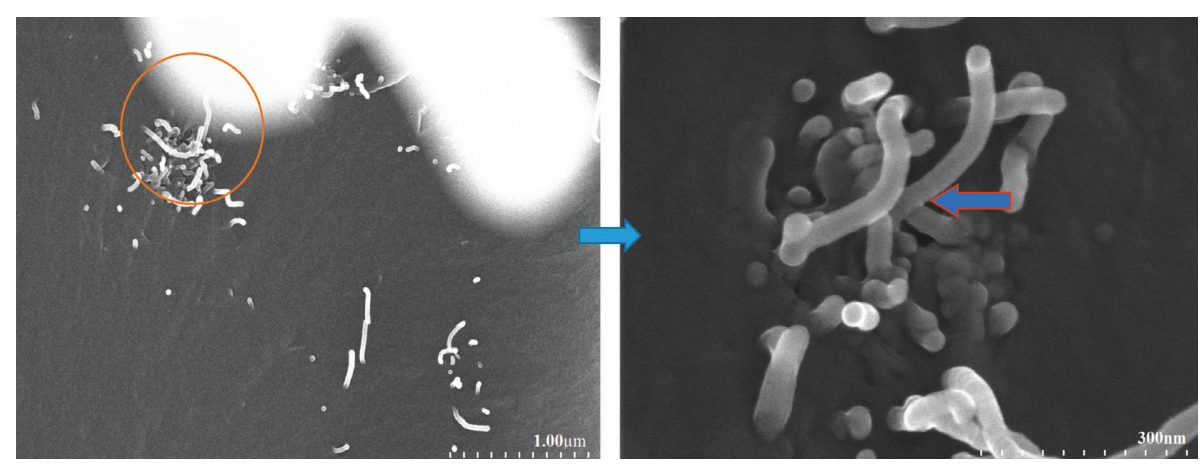

Figure 10: FE-SEM of MWCNTs/epoxy Epikote 240 nanocomposites.
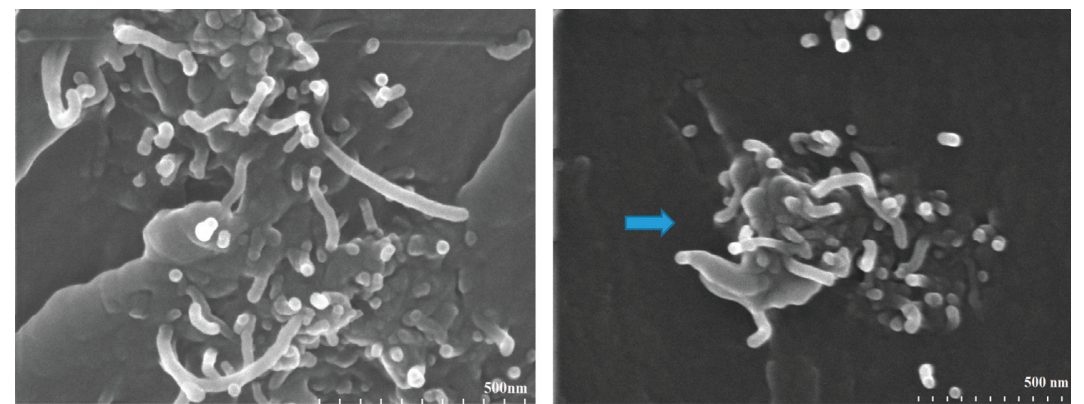

FIgURE 11: FE-SEM of MWCNTs/epoxy Epikote 240 nanocomposites.

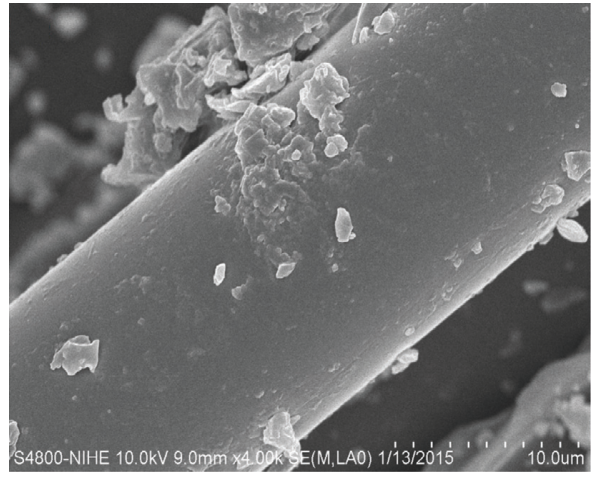

(a)

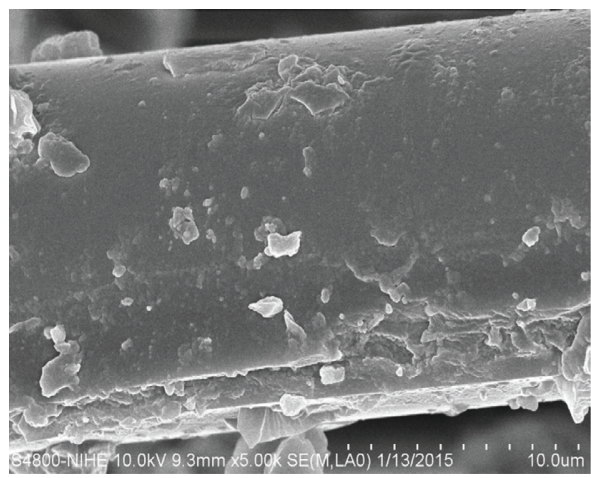

(c)

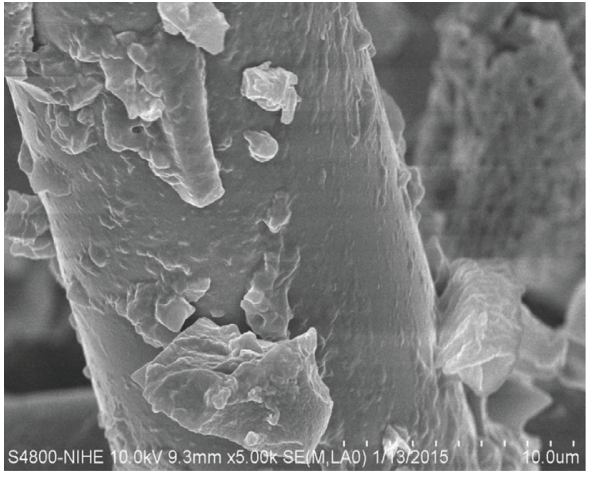

(b)

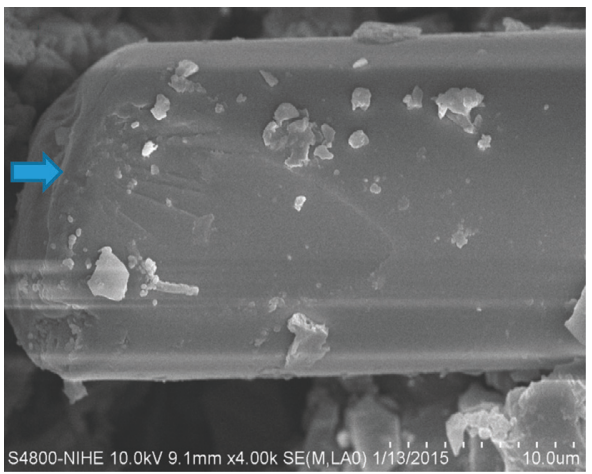

(d)

FIGURE 12: FE-SEM micrographs of fractured fiber of (a-e) glass/epoxy composites; (b) 2 wt.\% nanoclay/e-glass/epoxy composites; (c) 0.02 wt.\% MWCNTs/e-glass/epoxy composites; and (d) 2 wt.\% nanoclay/0.02MWCNTs/e-glass/epoxy composites. 
I.30E reinforced with glass cloth. Evaluate adhesion between epoxy base material (dispersed MWCNTs and nanoclay) and glass fiber-reinforced substance. The adhesion between substrate and reinforcement (MWCNTs, nanoclay, and glass fiber) plays an important role for the mechanical strength and fire resistance of nanocomposite-reinforced fiberglass materials. It may be directly related to the roughness of the fracture surface where crack development occurs [10].

\section{Conclusions}

Results show that epoxy resin with an improved flameretardant property was prepared by addition of nanoclay I.30E and MWCNT. In conclusion, mechanical properties and flame retardancy of epoxy resin were significantly improved by nanoclay I.30E/MWCNT additives. MWCNT and nanoclay I.30E uniformly distributed in epoxy resin form ash layers covering in material surface and preventing the contact between oxygen and the materials, limiting the development of flame. It can be said that the distribution ability of retardants in binders is more uniform, mechanical and retardant properties of materials are more improved. Thus, better dispersion and enhanced interfacial bonding between epoxy, MWCNT, nanoclay I.30E, and e-glass fibers leads to the improvement in thermomechanical and flexural properties of epoxy and consequently of glass/epoxy composites.

\section{Data Availability}

For any questions relating to the data or the original data requirements of the article, contact the corresponding author at anhtn.haui@gmail.com (anhnt@haui.edu.vn).

\section{Conflicts of Interest}

The authors declare that they have no conflicts of interest.

\section{Acknowledgments}

The authors wish to thank the Faculty of Chemical Technology, Hanoi University of Industry, for funding this work.

\section{References}

[1] H. Azman, M. K. Siti, M. Zurina, S. Zalilah, M. Munirah, and A. Faiz, "Exploring the effects of nanofillers of epoxy nanocomposite coating for sustainable corrosion protection," Chemical Engineering Transaction, vol. 72, pp. 121-126, 2019.

[2] L. Jie, Y. Haiou, W. Xin et al., "Charing polymer wrapped carbon nanotubes for simultaneously improving the flame retardancy and mechanical properties of epoxy resin," Polymer, vol. 52, no. 21, pp. 4891-4898, 2011.

[3] D. Bettina, W. Karen-Alessa, H. Daniel, M. Rolf, and S. Bernhard, "Flame retardancy through carbon nanomaterials: carbon black, multiwall nanotubes, expanded graphite, multi-layer graphene and graphene in polypropylene," Polymer Degradation and Stability, vol. 98, pp. 1495-1505, 2013.

[4] F. Laoutid, L. Bonnaud, M. Alexandre, J.-M. Lopez-Cuesta, and P. Dubois, "New prospects in flame retardant polymer materials: from fundamentals to nanocomposites," Materials Science and Engineering: R: Reports, vol. 63, no. 3, pp. 100-125, 2009.

[5] K. Cevdet, G. Ipek Nakas, and A. I. Nihat, "Mechanical properties, flammability and char morphology of epoxy resin/ montmorillonite nanocomposites," Applied Clay Science, vol. 46, pp. 319-324, 2009.

[6] M.D. Tomić, B. Dunjić, V. Likić, J. Bajat, J. Rogan, and J. Djonlagić, "The use of nanoclay in preparation of epoxy anticorrosive coatings," Progress in Organic Coatings, vol. 77, no. 2, pp. 518-527, 2014.

[7] M. M. Shokrieh, A. R. Kefayati, and M. Chitsazzadeh, "Fabrication and mechanical properties of clay/epoxy nanocomposite and its polymer concrete," Materials and Design, vol. 40, pp. 443-452, 2012.

[8] S. K. Lee, B. C. Bai, J. S. Im, S. J. In, and Y.-S. Lee, "Flame retardant epoxy complex produced by addition of montmorillonite and carbon nanotube," Journal of Industrial and Engineering Chemistry, vol. 16, no. 6, pp. 891-895, 2010.

[9] A. Montazeri, K. Pourshamsian, and M. Riazian, "Viscoelastic properties and determination of free volume fraction of multiwalled carbon nanotube/epoxy composite using dynamic mechanical thermal analysis," Materials and Design, vol. 36, pp. 408-414, 2012.

[10] V. K. Srivastava, "Modeling and mechanical performance of carbon nanotube/epoxy resin composites," Materials and Design, vol. 39, pp. 432-436, 2012.

[11] S. Zainuddin, A. Fahim, T. Arifin et al., "Optimization of mechanical and thermo-mechanical properties of epoxy and E-glass/epoxy composites using NH2-MWCNTs, acetone solvent and combined dispersion methods," Composite Structures, vol. 110, pp. 39-50, 2014. 

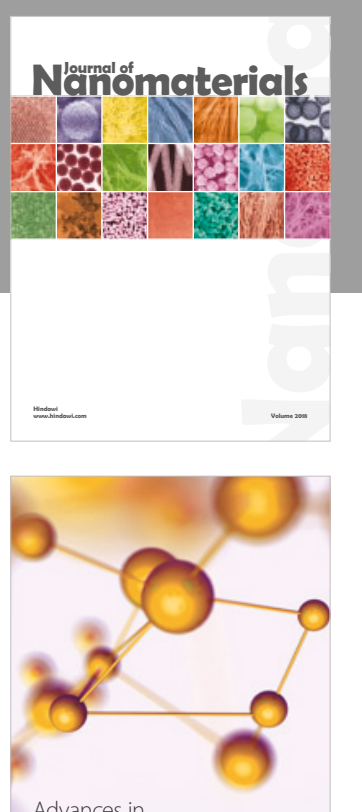

Physical Chemistry
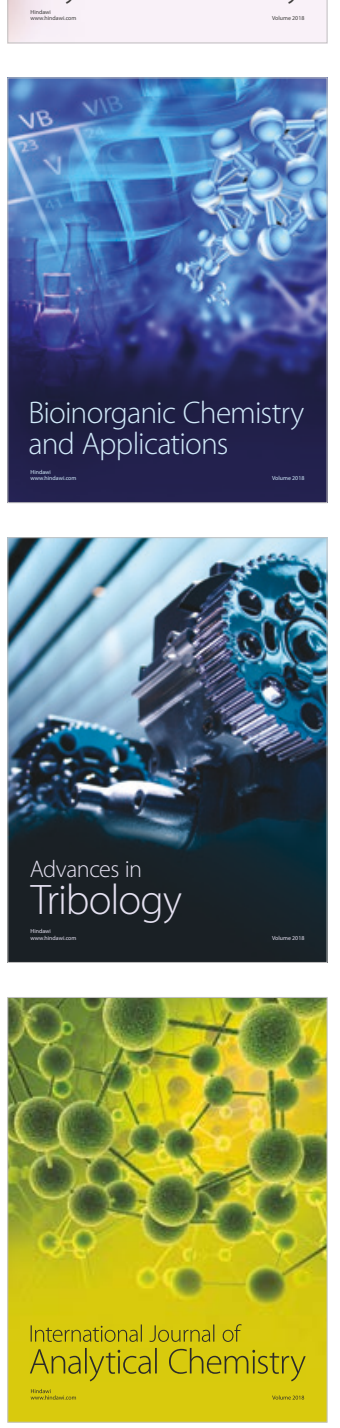

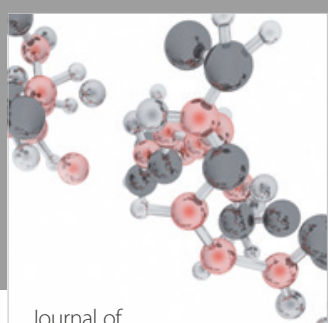

Analytical Methods

in Chemistry

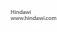

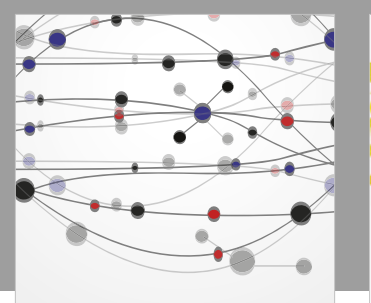

The Scientific World Journal

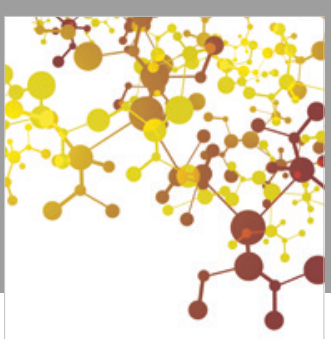

Journal of

Applied Chemistry
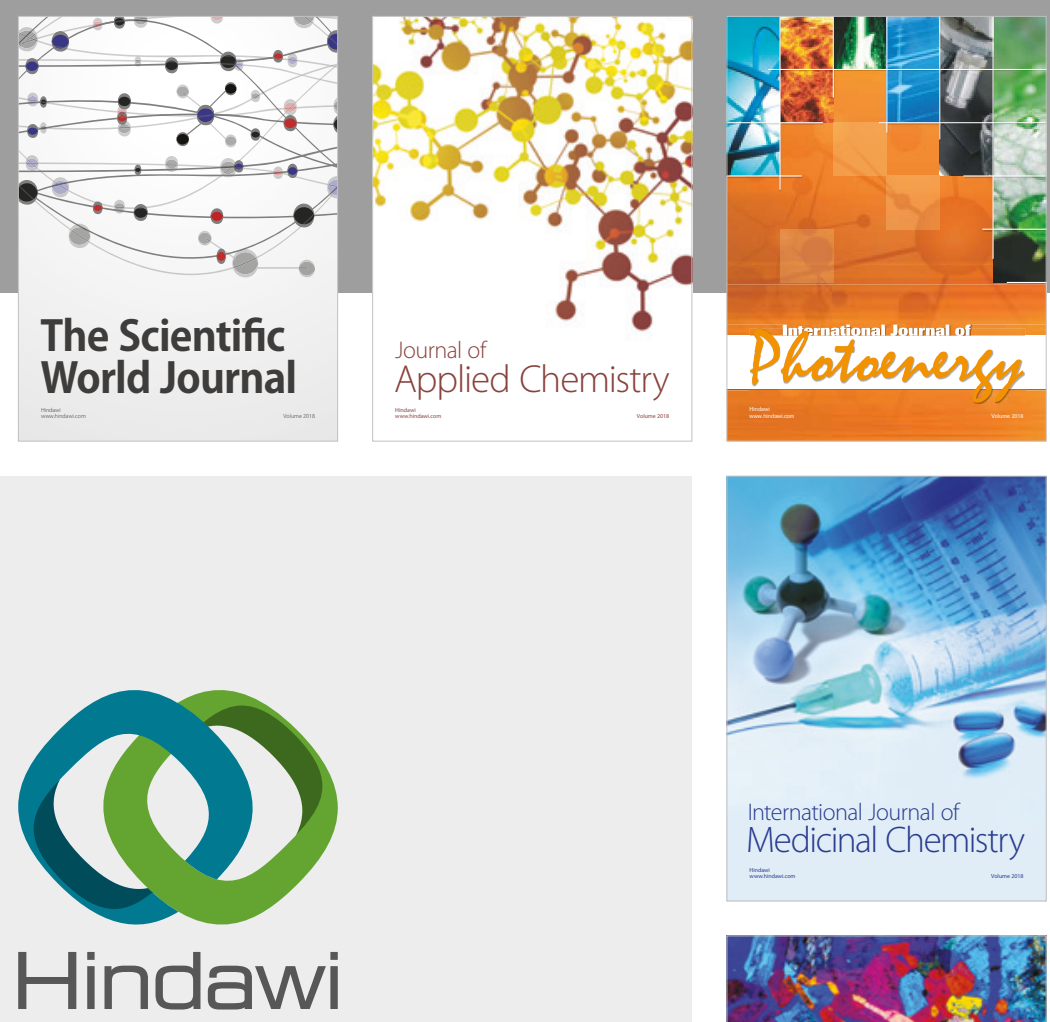

Submit your manuscripts at

www.hindawi.com
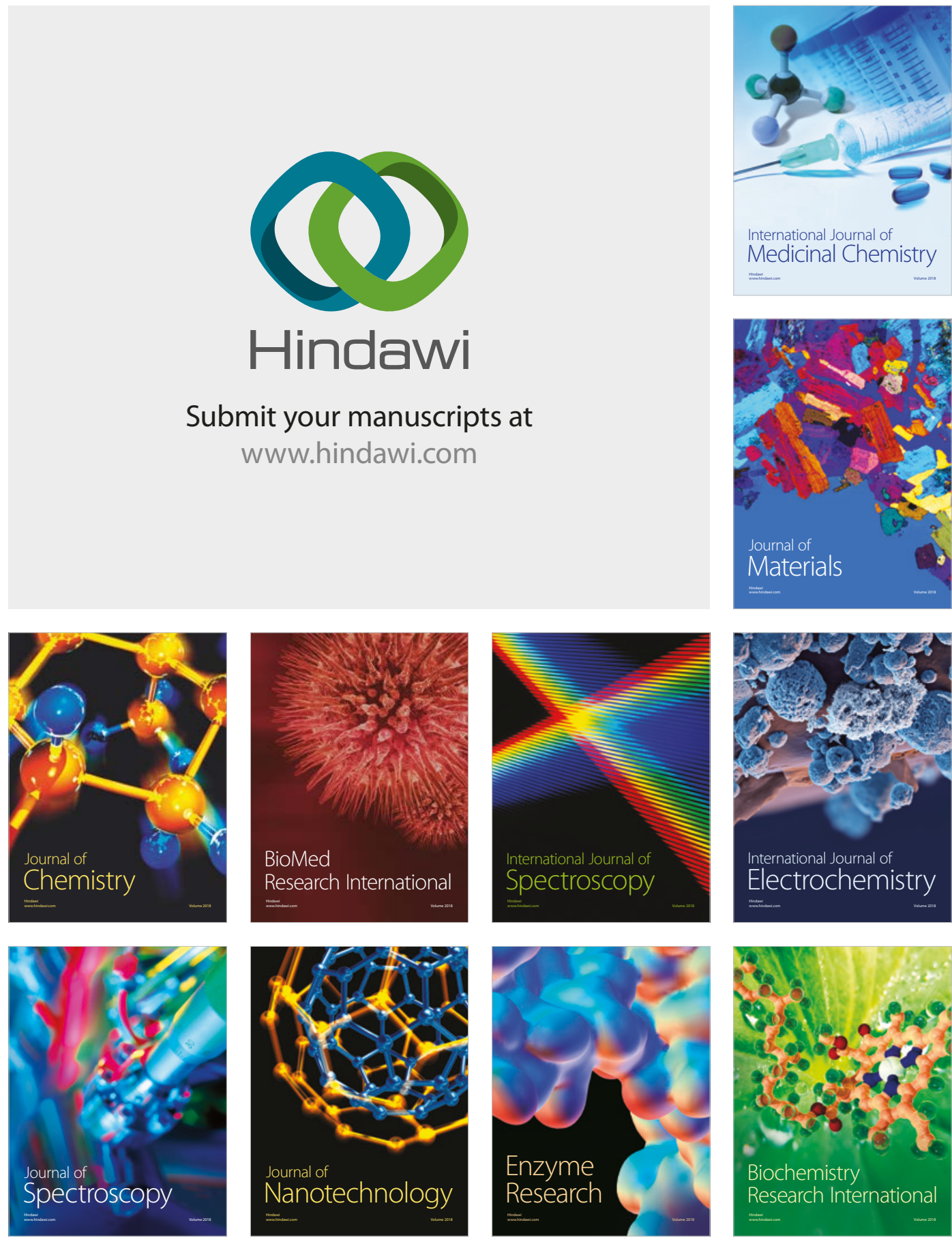
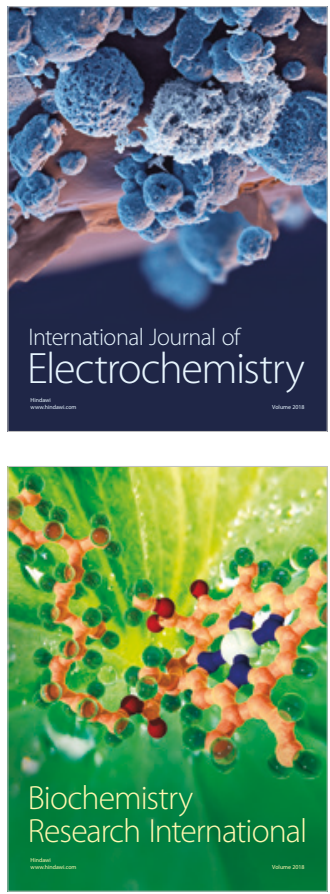